\title{
TIPOLOGÍAS DE PERCEPCIÓN, BAJO CRITERIOS DE SUSTENTABILIDAD TERRITORIAL, DEL PROCESO DE OCUPACIÓN URBANO-RURAL: LOCALIDAD QUINTA DE BOGOTÁ
}

\author{
Evelin Langebeck Cuéllar ${ }^{1}$ \\ Julio Beltrán Vargas ${ }^{2}$
}

Recibido el 11 de mayo de 2015, aprobado el 26 de octubre de 2015 y actualizado el 24 de mayo de 2016

\section{DOI: 10.17151/luaz.2016.43.18}

\section{RESUMEN}

En la localidad de Usme (Bogotá, Colombia) la tendencia de ocupación territorial ha sido la autogestión y autoconstrucción de las viviendas, lo que ha generado problemas socioambientales, que desencadenan la crisis de la sustentabilidad. En este sentido, el objetivo de esta investigación es identificar las percepciones de la población de la localidad de Usme frente al proceso de ocupación urbano-rural, bajo criterios de sustentabilidad territorial, con el fin de formar grupos de acuerdo a sus percepciones y ubicarlos en planos factoriales para su interpretación. Para ello, se utilizaron herramientas de toma de información, como la entrevista semiestructurada y la encuesta. La primera, se analizó mediante la técnica de análisis de contenido con el software ATLAS.ti $7 ®$, y la segunda, con la técnica estadística de análisis de correspondencias múltiples con el software DtmVic 5.7®, para generar la correspondiente tipificación. Se obtuvo cinco grupos o clúster. El grupo 5 asoció mayor cantidad de variables con un $44,62 \%$, representado por la UPZ Comuneros, definida por considerar como principal actividad contaminante el Relleno Sanitario Doña Juana, y atribuir el crecimiento de la localidad al desplazamiento forzado y la urbanización de tipo informal. En contraste, el grupo 1 asoció menor cantidad de variables con un 3,8\%, estando representado por de la UPZ Ciudad Usme y zona rural, quienes atribuyen como principal actividad contaminante la urbanización de tipo legal, que ha propiciado el crecimiento urbano, debido a los intereses políticos y privados. Por lo tanto, se puede señalar que se percibe de manera diferenciada la forma de ocupación y, a su vez, las condiciones socioambientales que ocurren en cada UPZ de la localidad. 


\title{
PALABRAS CLAVE
}

Tipologías, ocupación urbano-rural, sustentabilidad territorial, Usme.

\section{TYPES OF PERCEPTION WITH TERRITORIAL SUSTAINABILITY CRITERIA, OF THE PROCESS OF OCCUPANCY URBAN - RURAL: FIFTH DISTRICT OF BOGOTÁ.}

\begin{abstract}
In Usme (Bogotá, Colombia) the trend of settlement has been self-management and self-help housing, which has led to social and environmental problems that trigger the crisis of sustainability. In this sense, the objective of this research is to characterize the perceptions of the population of the district, about the occupation process of urban-rural, under territorial sustainability criteria, in order to form groups according to their perceptions and place them on factorial planes for interpretation and identification of variables. To do this, was used as source information, the semi-structured interview and survey. The first, was analyzed by content analysis technique with ATLAS.ti $7 \circledR$ software, and second, with the statistical technique of multiple correspondence analysis with software DtmVic $5.7 \AA$, to generate the appropriate classification. Five groups were obtained. The group with most variables associated with an $44.62 \%$ was the number 5 , represented by the Comuneros UPZs, defined by considering main polluting activity Doña Juana Landfill, and attribute the growth of the district, to forced displacement and informal urbanization. In contrast, group 1, variables associated were $3.8 \%$, is represented by the UPZ City and rural Usme, who attributed as the main polluting activity, urbanization formal, which it has attracted the urban growth, for political and private interests. Therefore, it can be noted that perceive differently the form of occupation of the town and in turn, the socio-environmental conditions given in each UPZ of the town.
\end{abstract}

\section{KEY WORDS}

Typologies, urban-rural occupancy, territorial sustainability, Usme. 


\section{INTRODUCCIÓN}

El $80 \%$ de la población de América Latina y el Caribe habita en zonas urbanas (Winchester, 2006; ONU, 2014). En la región, los procesos de planificación territorial se han realizado sin tener en cuenta los recursos naturales, y la incidencia de estos en la calidad de vida. En consecuencia, Colombia ha obedecido a un modelo territorial individual y sectorizado, que ha generado asentamientos precarios (Conpes 3305, 2004). La ciudad de Bogotá no escapa a esta tendencia, y es así como la localidad de Usme es el reflejo de un modelo territorial en la periferia de la ciudad, en donde los asentamientos dan la sensación de no hacer parte de la red urbana, y cuya opción de ocupación ha sido la autoconstrucción (Zambrano, 2005).

Lo anterior, se manifiesta en condiciones sociales y de calidad de vida, ya que los estratos predominantes en la localidad de Usme son: bajo, con un $53,54 \%$, y bajobajo, con un 44,93\%, según la proyección del año 2005 del DANE (2007). Por su parte, las Necesidades Básicas Insatisfechas son superiores a lo observado para Bogotá, así como el ingreso disponible, tiempos de movilidad y el acceso oportuno a bienes y servicios, los cuales son inferiores al promedio distrital (Hospital de Usme, 2011). Se suman las cargas ambientales, como el Relleno Sanitario Doña Juana (RSDJ) y el Parque Minero Industrial que, en su actividad, contaminan la cuenca baja del río Tunjuelo. A su vez, en materia urbanística la declaración de suelo de expansión urbana de las veredas Uval, Olarte y Los Soches, quienes recibirán población proveniente de otras zonas de la ciudad y regiones, con el fin de propiciar un desarrollo ordenado que compita contra la urbanización informal (Alcaldía Mayor de Bogotá, 2011).

En consecuencia, la implementación de políticas para resolver los problemas urbanos requiere información, que en la mayoría de ciudades no existe (Rodríguez, López \& Vela, 2013), por lo tanto es necesario realizar un proceso de identificación y tipificación de percepciones locales frente al proceso de ocupación urbano-rural, pues en las estadísticas y fuentes de información para la toma de decisiones no se contempla la información local. Por ende, el generar este tipo de información, validada en el territorio, permite concebir procesos participativos de evaluación y planificación territorial (Guitiérrez \& Peña, 1996; Ortiz \& Hernández, 2015).

Bajo el enfoque teórico de Fernández (2000), la metropolización que sufren las ciudades latinoamericanas no ha permitido una adecuada gestión de los procesos de ocupación, bajo criterios de sustentabilidad territorial, proceso que desencadena 
la crisis de sustentabilidad de las ciudades. Por un lado, la crisis de la sustentabilidad primaria, que se define como la incapacidad de retener población de las regiones rurales y sus redes de asentamientos. Y, por otra parte, la crisis de sustentabilidad secundaria, la cual surge como consecuencia del exceso del flujo migratorio, con manifestaciones como la caída de la prestación de servicios urbanos (agua, tratamiento de residuos, manejo de basuras, equipamientos sanitarios y educativos, la falta de inserción a los procesos productivos, y la marginalización social en el consumo) desplegándose sobre los territorios de la interface urbano-rural.

En este sentido, la investigación para aproximarse a una noción de sustentabilidad territorial retoma conceptos como territorio, territorialidad y percepción. El primero, es entendido como el espacio apropiado por un grupo social, en donde se asegura la reproducción y la satisfacción de las necesidades vitales, ya sean simbólicas o materiales (Giménez, 2001). La territorialidad, para Ther Ríos (2012), son los comportamientos en el territorio de los medios, elementos y motivaciones con que se llega a habitar y a permanecer en un espacio, en donde se crean formas de vida e interacciones con lo ambiental y con otros. Lo anterior, permite que los sujetos establezcan sentidos, opiniones y conductas sobre su entorno, en este caso lo que Gutiérrez \& Peña (1996) denominan como percepción. A su vez, se establece que la percepción depende de las comunidades, del lenguaje y las visiones del mundo, que están influenciadas por los afectos y las expectativas de las personas (Cano, 2012). En esta investigación, la sustentabilidad territorial se entiende como la capacidad que tienen los actores locales de gestionar colectivamente su desarrollo o proyecto de vida, dirigida a la construcción de estrategias inclusivas y de movilización social, buscando habilidades de producción que no afecten su territorio y el de los demás (Dematteis \& Governa, 2005), y que se obtenga como resultado la sostenibilidad de la calidad de vida de la sociedad (Galopín, 2006). Por lo tanto, el objetivo de este manuscrito es identificar las percepciones de la población de la localidad de Usme frente al proceso de ocupación urbano- rural, bajo criterios de sustentabilidad territorial, con el fin de formar grupos de acuerdo a sus percepciones y ubicarlos en planos factoriales para su interpretación. 


\section{MATERIALES Y MÉTODOS}

\section{Área de estudio}

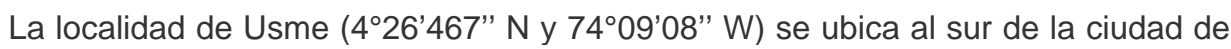
Bogotá (Colombia), en el sistema montañoso de la cordillera Oriental andina, entre los 2600 y los $3100 \mathrm{msnm}$. La temperatura anual promedio es de $7^{\circ} \mathrm{C}$ a $12^{\circ} \mathrm{C}$. Posee una extensión total de 21.507 ha, de las cuales 3.029 son suelo urbano y 18.477 suelo rural. Administrativamante se conforma por las siguientes UPZ3: La Flora (52), Danubio (56), Gran Yomasa (57), Comuneros (58), Alfonso López (59), Parque Entre Nubes (60), Ciudad Usme (61) y área rural (Figura 1) (Alcaldía Mayor de Bogotá, 2004).

\section{METODOLOGÍA}

La investigación se desarrolló en dos fases. Una fase exploratoria, en donde se realizó la búsqueda sistemática de artículos científicos y documentos relacionados al proceso de ocupación urbano-rural. Consecutivamente, se estructuró la entrevista piloto, como primer acercamiento para reconocer la percepción de la población local. Las preguntas fueron de tipo abierto, las cuales se elaboraron de acuerdo a dimensiones relacionadas al proceso de ocupación, bajo criterios de sustentabilidad territorial como: físico ambiental, social y de calidad de vida, institucional y de percepción local. En la fase de campo, se entrevistaron a líderes comunitarios, organizaciones sociales y residentes permanentes de la localidad, que quisieron participar voluntariamente en la investigación (Grande \& Abascael, 2005). A continuación, se realizó la transcripción de las entrevistas y la codificación de los resultados, mediante el uso de la técnica de análisis de contenido. 


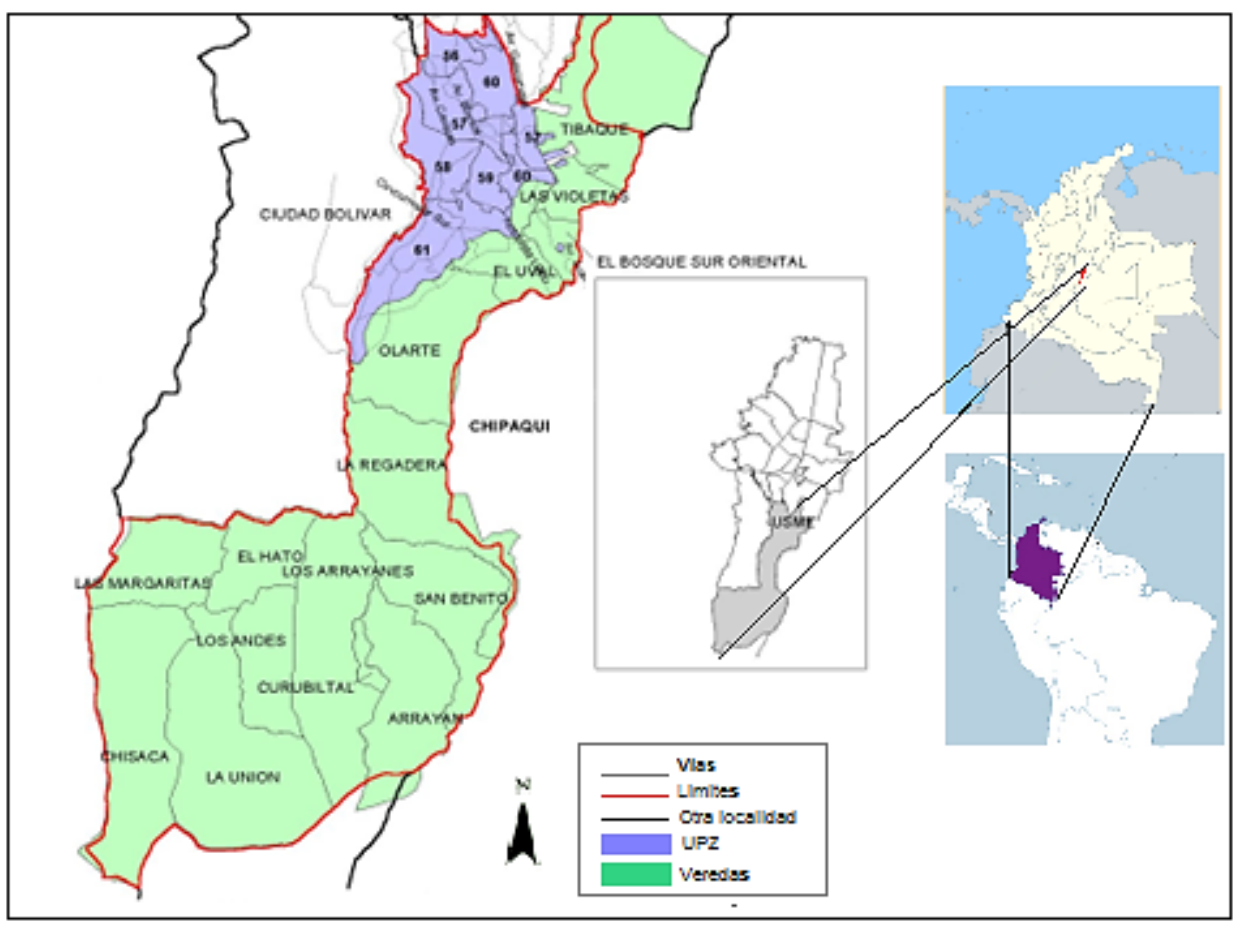

Fuente: modificado de Hospital de Usme (2003).

Figura 1. Área de estudio. Localidad de Usme.

La estructuración de la encuesta se realizó a partir de las variables identificadas de la entrevista piloto, se plantearon 23 preguntas cerradas, categorizadas de la siguiente manera: i) Adquisición, estado de vivienda y servicios urbanos; ii) Estado de los recursos naturales y conflictos ambientales; iii) Percepciones frente al proceso de ocupación territorial y crecimiento urbano en la localidad.

La aplicación de la encuesta se realizó por medio de recorridos sistemáticos por las UPZ en la localidad de Usme, en el transcurso del recorrido se contactaron las personas que accedieron a participar voluntariamente en la investigación (Hernández, Fernández \& Baptista, 1997). La aplicación de la encuesta tomó entre 8 a 10 minutos.

\section{Sistema de muestreo}

El tipo de muestreo fue no probabilístico (Grande \& Abascael, 2005). Por lo tanto, para determinar el tamaño muestral, se realizó el cálculo para una población infinita o desconocida mayor a 10.000. El universo de la muestra fue de 335.228 
habitantes, mayores de 15 años, de acuerdo a la proyección de la población del censo DANE, 2005. La ecuación que se utilizó para determinar la muestra es la siguiente (Echavarría, 2013):

$$
n=\frac{p * q * Z 2}{e 2}
$$

donde:

$\boldsymbol{n}$ : es el tamaño de la muestra.

$\boldsymbol{p}$ : es la proporción esperada que cumpla con la característica deseada.

q: es la proporción esperada que no cumple la característica deseada.

e: es el margen de error deseado.

Se realizaron un total de 70 encuestas, que se distribuyeron proporcionalmente al tamaño poblacional de las UPZ en la localidad.

\section{Análisis de la información}

La información proveniente de las entrevistas se analizó por medio de la técnica análisis de contenido, definida como la clasificación del contenido en categorías apropiadas para describir de forma ordenada un conjunto de materiales cualitativos, procedentes de registros de conductas (Martin, 2000). En una primera fase se utilizó el software MAXQDA® que permite codificar y sistematizar la información de datos textuales, para su posterior análisis de frecuencias y categorización de las respuestas dadas por los entrevistados. En una segunda fase se utilizó el software ATLAS.ti® que, además de codificar y sistematizar la información, permite realizar gráficos de relaciones o redes entre códigos para interpretar los resultados. Además, se generaron modelos, que apoyaron argumentaciones frente al proceso de ocupación territorial en la localidad de Usme (Varguillas, 2006).

Las encuestas se analizaron por medio de estadística descriptiva y el análisis de correspondencias múltiples, con el software DtmVic $5.7 \AA$, para realizar la tipificación de la percepción de la población local, frente al proceso de ocupación urbano-rural (Vera, Camino, Baez \& Lerdon, 2002). De acuerdo a Crivisqui (1999), el análisis de correspondencias múltiples es una técnica que permite la reducción de dimensiones, en este caso el número de preguntas de la encuesta, cuyo objetivo principal es situar los datos en planos factoriales y analizar cómo se 
organizan alrededor de los centros de gravedad. Para ello, se realizó un pretratamiento de los datos, por medio de la elaboración de una matriz en Excel. A continuación se codificaron las respuestas de la encuesta, de acuerdo a los lineamientos del software, para generar una tabla de datos. En consecuencia, se generaron los archivos en formato block de notas, para realizar el análisis de correspondencias múltiples. Se escogieron 16 variables, tras diferentes modelaciones, las cuales permitieron encontrar mayores diferencias entre los grupos o clúster conformados (Vera et al., 2002). Finalmente se generaron los planos factoriales, los cuales permitieron analizar y sintetizar la información (Pardo, Ortiz \& Cruz, 2012; Lebart \& Piron, 2013).

\section{RESULTADOS}

Identificación de variables del proceso de ocupación en la zona quinta de Bogotá, por medio de la entrevista piloto

Inicialmente, para el análisis de las entrevistas, se utilizó el software MAXQDA®, que generó un sistema de códigos, para un posterior análisis de frecuencias, respecto a cada pregunta de la entrevista. Se identificó que los códigos relevantes para la población local son los que asociaron mayores frecuencias y generaron mayor discusión en sus respuestas, estos son los que se visualizan en la Figura 2. 


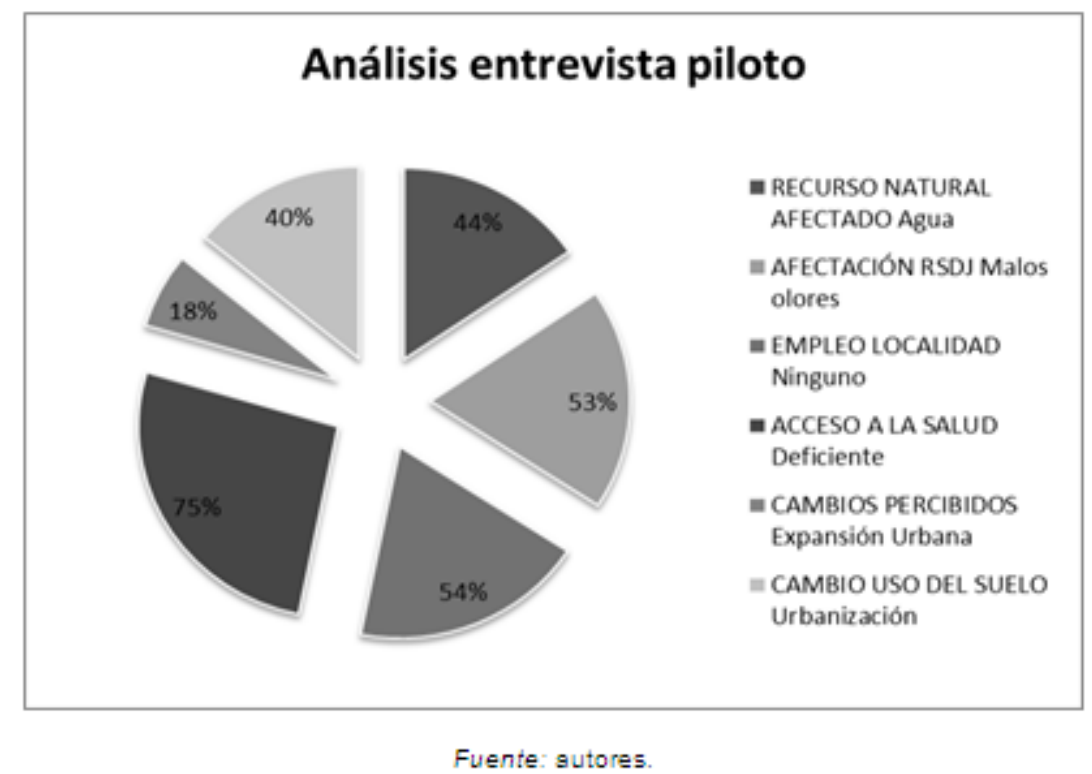

Figura 2. Análisis de frecuencias entrevista piloto.

En la dimensión físico-ambiental se determinaron como prioritarias las siguientes variables: el recurso natural agua como el más afectado en la localidad y afectación del RSDJ por los malos olores, con $44 \%$ y $53 \%$ respectivamente (Universidad del Valle, 2006). Por otro lado, en la dimensión social y de calidad de vida, se determinaron variables como la percepción negativa frente el acceso a la salud con un $75 \%$, ya que los entrevistados establecen que en la localidad no existe un hospital de nivel II o III, y la población es atendida por los centros de atención primaria en salud, que no son lo suficientemente capacitados para las problemáticas que se presentan. A su vez, se identifica la falta de empleo en la localidad con un $54 \%$. Frente a la dimensión de percepción local, los entrevistados asociaron la expansión urbana como el mayor cambio percibido con un $18 \%$. A su vez, el cambio de uso del suelo en la localidad lo asociaron al aumento de la urbanización con un 40\% (Hospital de Usme, 2011).

En seguida del análisis de frecuencias, se procede a realizar un gráfico de red o Networks para comprender las relaciones de ciertas variables o códigos, y así aproximar los factores de las causas de la ocupación del territorio en la localidad. Se utilizó el software ATLAS.ti 7@ para el análisis de datos cualitativos, por medio de la codificación, la segmentación del texto en pasajes o citas (Muñoz, 2003). Se generaron diferentes gráficos que respondían a las dimensiones anteriormente expuestas, como físico-ambiental, social y de calidad de vida, institucional y de percepción local, para crear un gráfico de aproximación a causas del proceso de 
ocupación. En este, se observan relaciones entre códigos como "is part of", que indica que un código hace parte del otro, o que lo contiene. También, se encuentra la relación "is associated with", que indica una asociación ente códigos, y por último la relación "if cause of", que muestra cómo un código desencadena o causa la aparición de otro, como se muestra en la Figura 3.

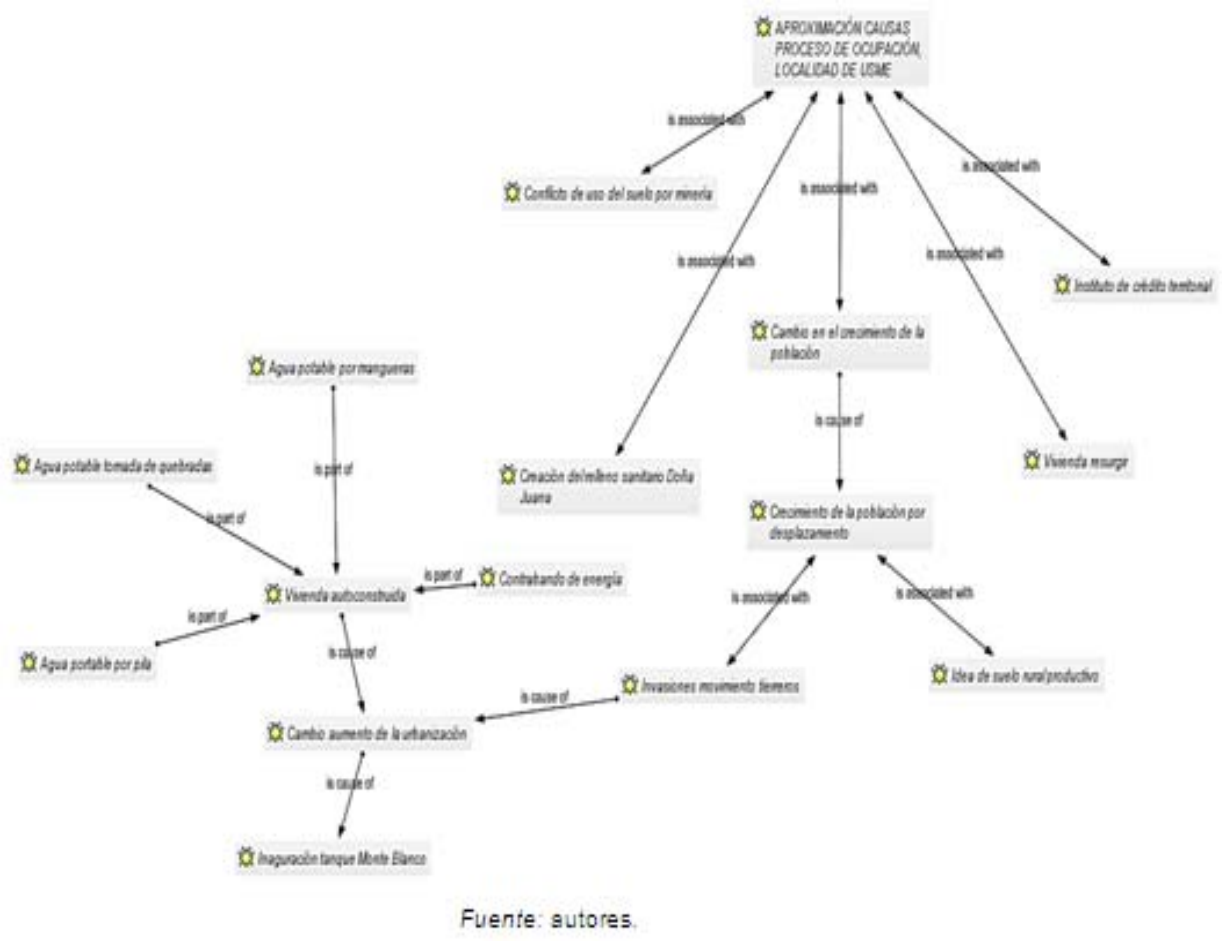

Figura 3. Aproximación a causas del proceso de ocupación en la localidad de Usme.

ATLAS.ti $7^{*}$.

Haga clic sobre la imagen para ampliarla

Entre las variables identificadas por las personas entrevistadas, se encuentra el conflicto de uso del suelo por minería, que ha sido una de las actividades industriales de tradición, la cual genera conflictos ambientales. También, se identificó la creación del RSDJ como un condicionante de la ocupación de la localidad, ya que se considera como una carga ambiental que fomenta la segregación socioespacial.

(...) aquí podríamos decir que tenemos cargas ambientales no bien distribuidas en la ciudad, es que al sur de Bogotá tenemos la minería, el relleno sanitario, ladrilleras informales, tenemos la segregación social, con 
vivienda de interés social, digamos abusiva con el territorio sin equipamientos, y sin equilibrio paisajístico, aquí con esas cargas ambientales lo que existe es unas determinantes económicas y sociales que nos segregan y eso lo que implica no solo es el hecho de una mala calidad ambiental, sino el hecho de una segregación socioespacial que impide el desarrollo integral de la localidad (...). (Comunicación personal, 19 de marzo de 2014)

Otra de las variables identificadas es la adquisición formal de vivienda (Instituto de Crédito Territorial y vivienda Resurgir), que generó otra manera de ocupación, en donde se contaba con los servicios públicos básicos.

(...) desde que llegamos aquí hemos tenido buen servicio de agua y de luz. (Comunicación personal, 14 de marzo de 2014)

Ingeniobras nos entregó nuestras casas, estoy hablando de las 130 familias, nos entregó nuestras casas, con el Agustín Codazzi tuvimos un acceso muy fácil porque ya estaba poblada La Aurora, al gas, al agua, la energía fue muy fácil (...). (Comunicación personal, 23 de marzo de 2014)

En los últimos años, el crecimiento poblacional se debe principalmente a la población desplazada, que llega a la localidad por medio de intermediarios como el movimiento de Tierreros, que se apropian de predios no aptos para urbanizar y posteriormente los venden a muy bajos precios (SDA, 2008). En la Figura 5 se muestra la vivienda autoconstruida en la localidad, barrio Barranquillita, UPZ Yomasa.

(...) alrededor de Tunjuelo, ha sido una forma de apropiarse del territorio, ya que hubo un movimiento en el sur, llamado los Tierreros, como parte de un ejercicio de cuenca del río Tunjuelo, estas personas se apropiaron del territorio en función de la urbanización ilegal (...). (Comunicación personal, 19 de marzo de 2014) 


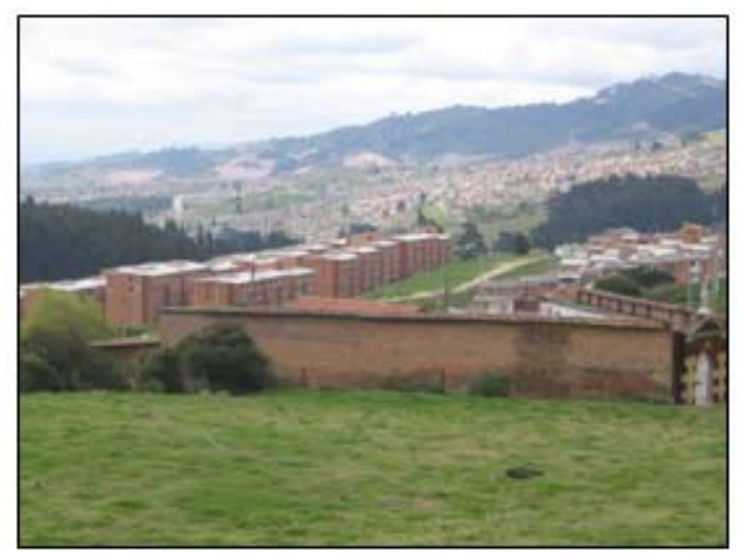

Fuente: autores.

Figura 4. Expansión urbana. Usme Pueblo. 2014.

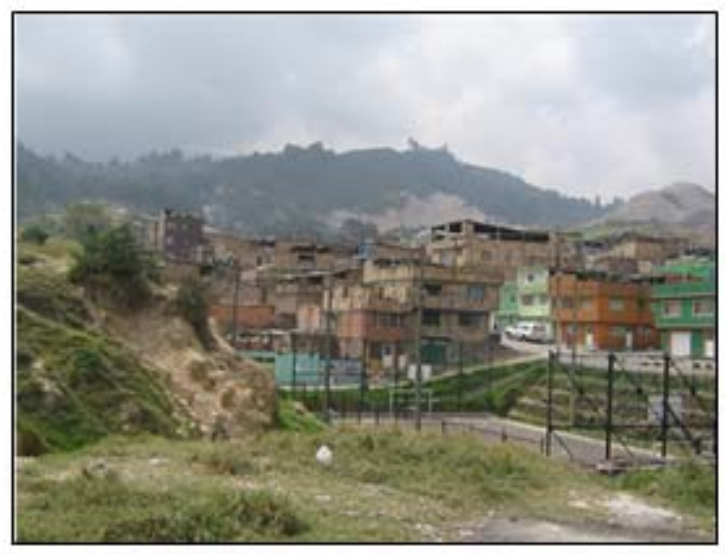

Fuente: autores.

Figura 5. Barrio Barranquillita. 2014.

Este movimiento de ocupación ilegal aumenta la urbanización de la localidad, y es así como la inauguración del tanque de Monte Blanco, realizado por el Acueducto de Bogotá, jalona la expansión de la localidad. Esta expansión lleva consigo el aumento de la urbanización, por medio de la autoconstrucción, originalmente en barrios que no habían sido planificados (Zambrano, 2005). En la Figura 4 se visualiza la expansión urbana actual en Usme Pueblo.

(...) cuando inauguraron el tanque de Monte Blanco, que nosotros protestamos, y cuando vinieron a inaugurar del acueducto el tanque fue tanta la gente que vino que los que estuvimos fue Gerardo Santafé, Catalina y un burro, nadie más llegó, porque nosotros no estábamos de 
acuerdo con eso, porque era la expansión. La expansión se ha dado y desde esa época siempre hemos peleado el pacto de bordes y franjas amarillas, pero no se ha escuchado, obviamente la expansión siempre ha existido, sino que nosotros ahora solo miramos hacia arriba porque ya acabaron con las veredas y ahorita ya se van a meter con La Requilina (...). (Comunicación personal, 15 de marzo de 2014)

Finalmente, la vivienda autoconstruida y bajo condiciones de ilegalidad, acceden al agua potable por medio de mangueras, pila comunitaria o directamente de las quebradas, a su vez, es concurrente el contrabando de energía. Generalmente estas viviendas se asentaban en las partes altas de las montañas y en las riberas de los ríos, buscando principalmente el acceso al agua (Zambrano, 2005).

(...) no teníamos servicios públicos, lo que era la quebrada de Yomasa era una cosa espectacular, cuando se empezó a urbanizar Santa Librada teníamos que recoger el agua en pila y un punto estratégico del agua donde estaban las pilas donde hoy es el colegio Almirante Padilla (...). (Comunicación personal, 15 de marzo de 2014)

(...) muy común el contrabando, lo mismo el agua, la llamada contrabando de luz, de agua y la televisión pirata. (Comunicación personal, 23 de marzo de 2014)

En la segregación de la periferia, sectores de invasión se pegan del poste, es una segregación ya no de desplazamiento sino violencia económica y social de la ciudad hacia los habitantes (...). (Comunicación personal, 19 de marzo de 2014)

A partir de las variables identificadas, por medio de la entrevista piloto se elaboró la encuesta, con el fin de obtener tipologías de la población frente a los fenómenos del proceso de ocupación territorial en Usme.

Tipificación de las percepciones de la población a partir de las variables identificadas

Un total de 70 habitantes de la localidad de Usme fueron encuestados. En la Figura 6 se presenta que el $58,57 \%$ de los encuestados son mujeres y el $41,43 \%$ son hombres. Se identificó que la mayor ocupación laboral es el trabajo como independiente en establecimientos comerciales en sus viviendas. El nivel de 
escolaridad predominante es bachillerato con un $44,20 \%$ y primaria con un $28,57 \%$.

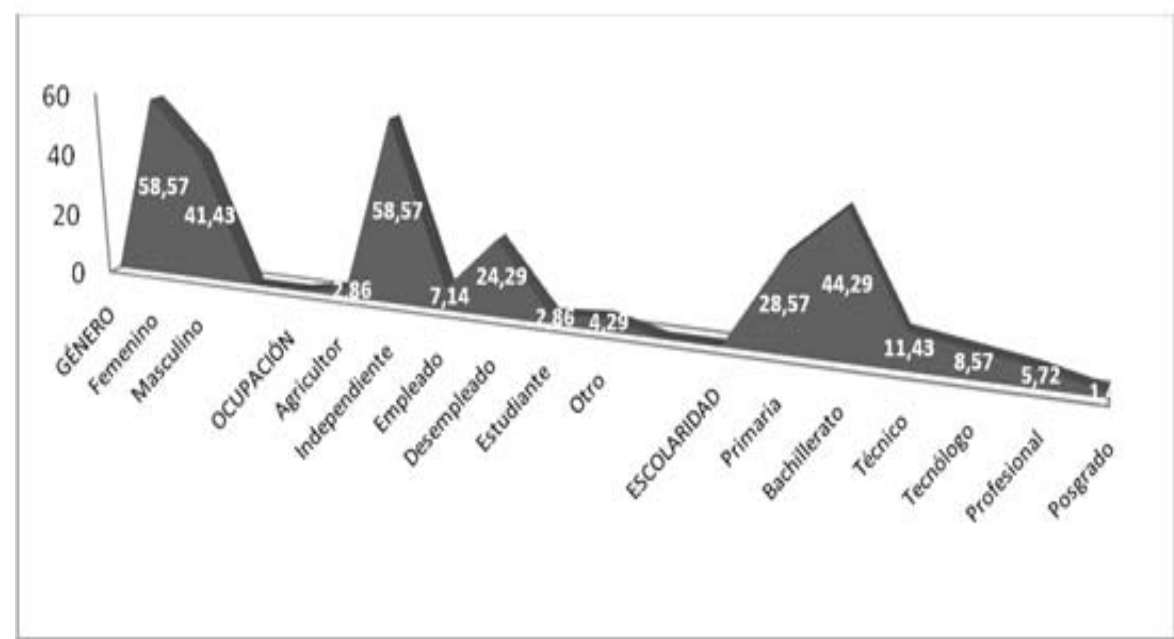

Fuente: autores.

Figura 6. Condiciones socioeconómicas de la población encuestada.

Inicialmente se escogieron 16 variables, que aportaron la mayor información. Estas se escogieron tras varias modelaciones en donde se comparaban los grupos formados, se escogieron aquellas que permitieron encontrar mayores diferencias y se decidió, finalmente, escoger las variables descritas en la Tabla 1. 
Tabla 1. Variables determinadas para el análisis de correspondencias múltiples

\begin{tabular}{|c|c|c|}
\hline & CATEGORIA DE SUSTENTABILIDAD & VARIABLE \\
\hline 1 & Socioeconómica & UPZ \\
\hline 2 & Adquisición de vivienda y servicios & Porqué llegó a vivir en la localidad \\
\hline 3 & urbanos & Cómo adquirió la vivienda \\
\hline 4 & \multirow{11}{*}{$\begin{array}{l}\text { Estado de los recursos naturales y } \\
\text { conflictos ambientales }\end{array}$} & $\begin{array}{l}\text { Actividad contaminante: Parque Minero } \\
\text { Industrial }\end{array}$ \\
\hline 5 & & Actividad contaminante: canteras y ladrilleras \\
\hline 6 & & Actividad contaminante: RSDJ \\
\hline 7 & & Actividad contaminante: urbanización informal \\
\hline 8 & & Actividad contaminante: urbanización legal \\
\hline 9 & & Aspecto crucial: desplazamiento forzado \\
\hline 10 & & Aspecto crucial: mejora del transporte público \\
\hline 11 & & Aspecto crucial: urbanización a precios bajos \\
\hline 12 & & Aspecto crucial: urbanización ilegal \\
\hline 13 & & $\begin{array}{l}\text { Aspecto crucial: construcción Centro Comercial } \\
\text { Altavista y Portal de Usme }\end{array}$ \\
\hline 14 & & Aspecto crucial: intereses políticos \\
\hline 15 & \multirow{2}{*}{$\begin{array}{l}\text { Percepciones frente al proceso de } \\
\text { ocupación }\end{array}$} & Forma de intervenir el territorio de Usme \\
\hline 16 & & Localidad siga urbanizándose \\
\hline
\end{tabular}

Fuente: autores.

Posteriormente, para realizar la tipificación de las percepciones de la población, se analizaron los dos ejes factoriales, debido a que los dos primeros ejes factoriales acumulan la mayor varianza explicada (Vera et al., 2002), donde sus porcentajes corresponden al 10,89\% para el primer eje $X$ o factor 1 , y el 9,91\% para el eje $Y$ o factor 2. Estos valores se presentan en laTabla 2. 
Tabla 2. Valores propios y porcentajes de los primeros ejes factoriales

\begin{tabular}{|c|c|c|}
\hline EJE & PORCENTAJE \% & PORCENTAJE ACUMULADO \% \\
\hline 1 & 10,89 & 10,89 \\
\hline 2 & 9,91 & 20,80 \\
\hline 3 & 7,54 & 28,34 \\
\hline 4 & 7,16 & 35,51 \\
\hline
\end{tabular}

Fuente: autores.

Se obtiene el dendrograma, a partir de la tipificación, que se aprecia en la Figura 7, en donde se realiza la agrupación y distribución de la población en cinco grupos que se constituyeron de acuerdo a las variables de la Tabla 1.

Paralelamente, en la identificación de tipologías de percepción de la población frente al proceso de ocupación en la localidad de Usme, se observa el plano factorial de individuos en laFigura 8. En donde se conformaron 5 grupos. Los números que se observan en el plano hacen referencia a las personas encuestadas, que se enumeraron de 1 hasta 70, siendo este el número total de encuestados. Cada grupo conformado posee características diferenciadas, las cuales se presentan en la Tabla 3. 

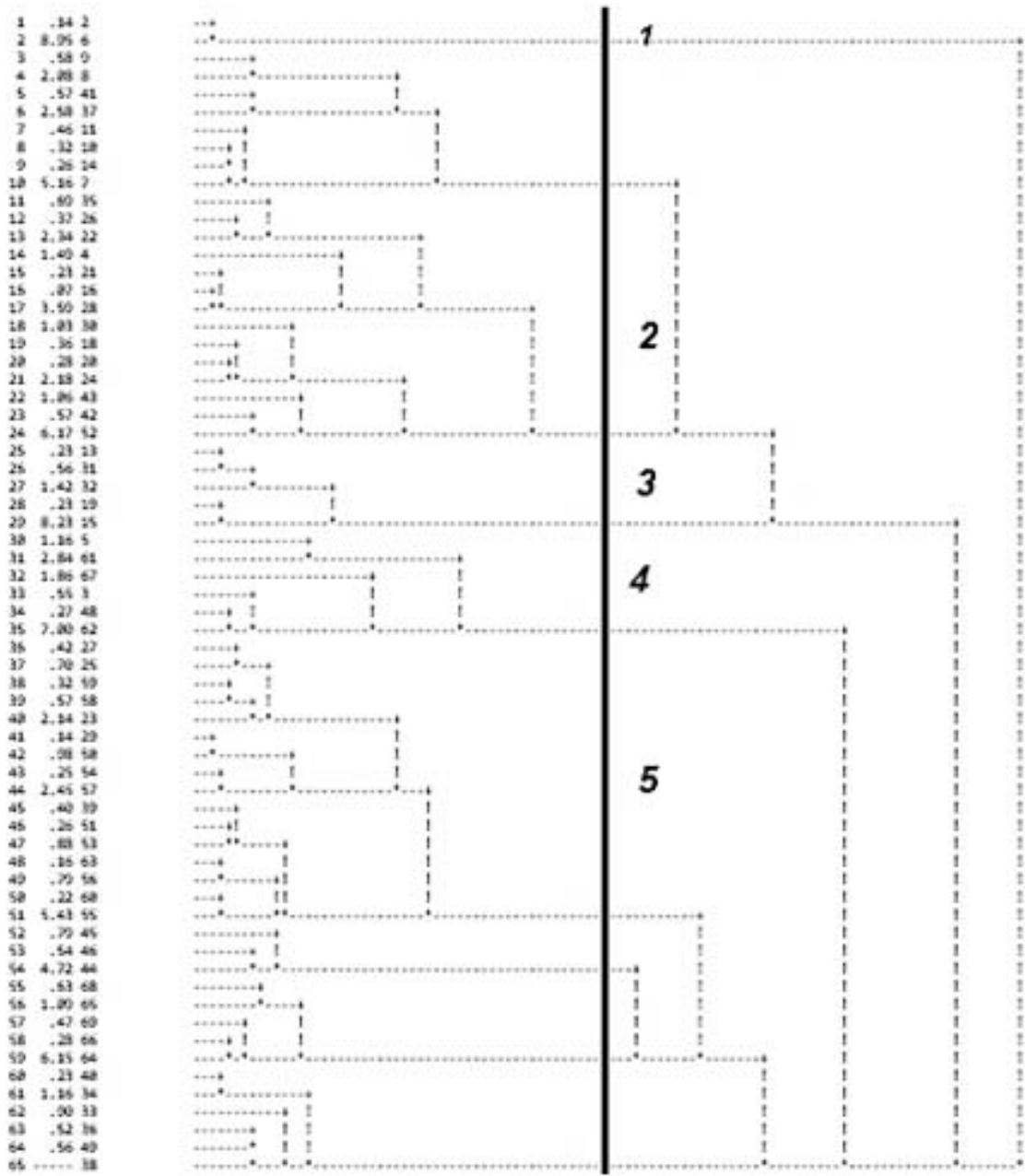

Fuente autores

Figura 7. Dendrograms. Software DtmVic 5.7. 
Tabla 3. Descripción de los clúster conformados

\begin{tabular}{|c|c|c|}
\hline GRUPO & FRECUEINCIA & CARACTERTSTICASDELOSGRUPOS \\
\hline 5 & $44,82 \%$ & 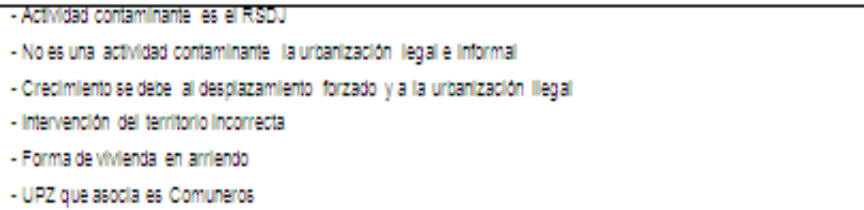 \\
\hline 2 & $33,85 \%$ & 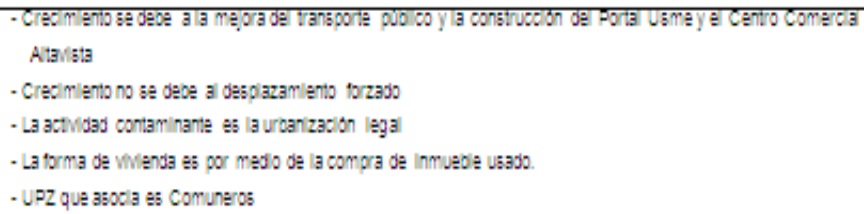 \\
\hline 4 & $70,77 \%$ & 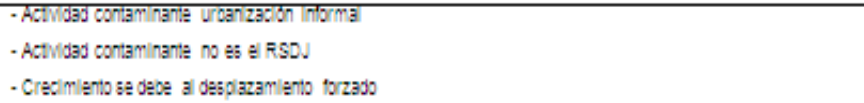 \\
\hline 3 & $7,69 \%$ & 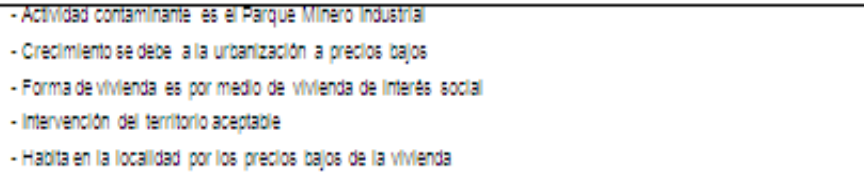 \\
\hline 1 & $3,8 \%$ & 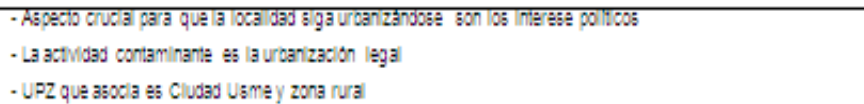 \\
\hline
\end{tabular}

Fuente: autores.

De acuerdo a la Figura 7 y la Tabla 3, el grupo 1 se caracteriza por un aspecto crucial que marca el crecimiento de la localidad, son los intereses políticos, y la principal actividad contaminante es la urbanización de tipo legal. En este grupo se encuentra la UPZ Ciudad Usme y zona rural, lo que concuerda con Hospital de Usme (2011) que argumenta que los habitantes de la zona rural perciben la expansión urbana con la operación estratégica Nuevo Usme, como un factor de deterioro de la calidad de vida, ya que además de tener que vender sus predios por debajo del valor real, el arribo de población de otros regiones y localidades genera problemas de inseguridad, pérdida de la identidad agrícola y cambio de uso del suelo. Por lo tanto, en el trabajo de campo, la población entrevistada de esta UPZ propuso que se incluyera esta variable relacionada como actividad impactante de tipo social y ambiental.

Por su parte, el grupo 2 se caracteriza porque el desplazamiento forzado no ha conducido al crecimiento de la localidad, sino que por el contrario asumen que se debe a la mejora del transporte público y la construcción del Centro Comercial Altavista y el Portal Usme. Asimismo, consideran como actividad contaminante la 
urbanización de tipo legal y la forma de adquirir la vivienda se debe a la compra de inmueble usado. La UPZ que representa a este grupo es Gran Yomasa.

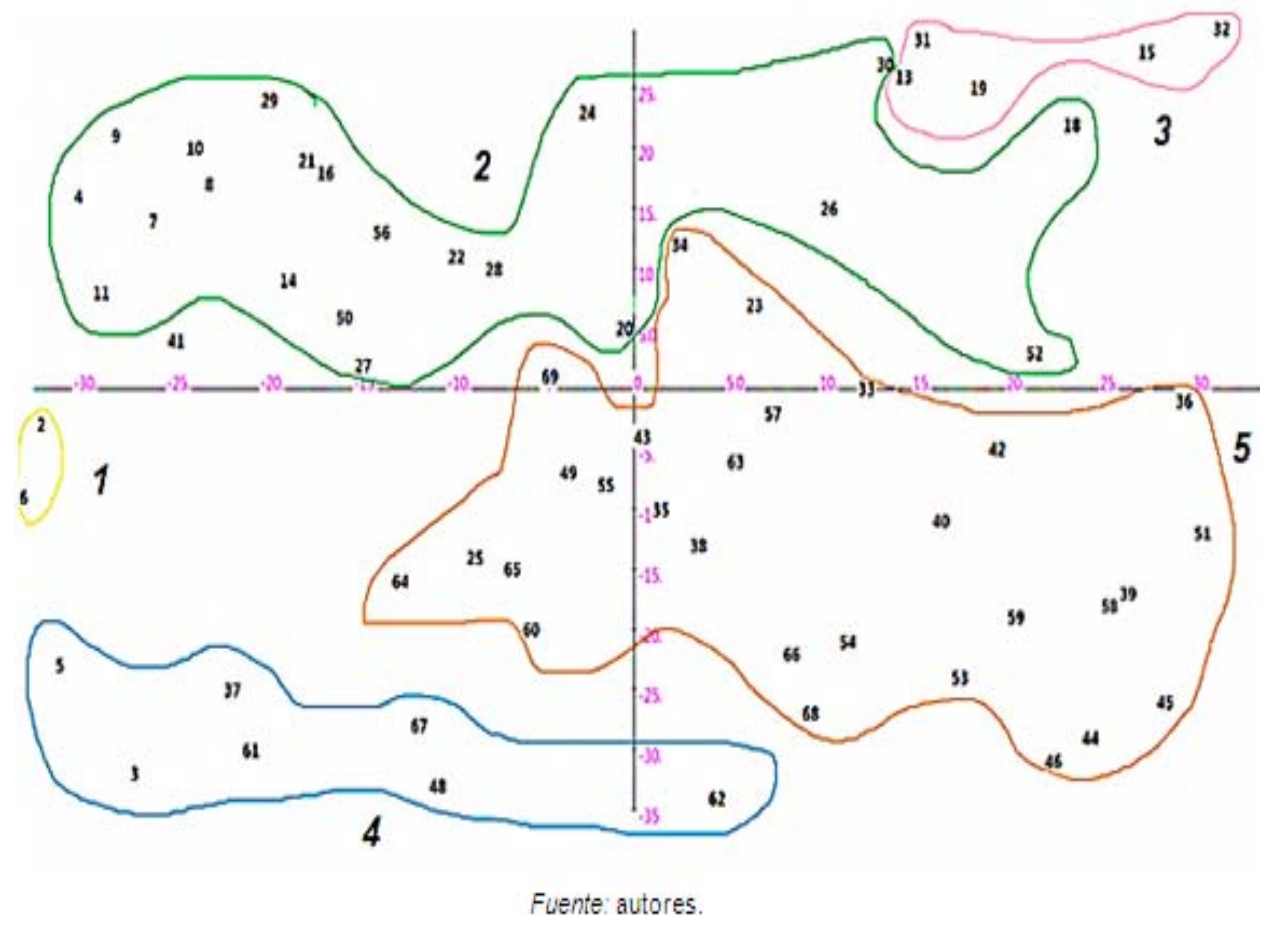

Figura 8. Plano factorial distribución de encuestados. DtmVic 5.7. 


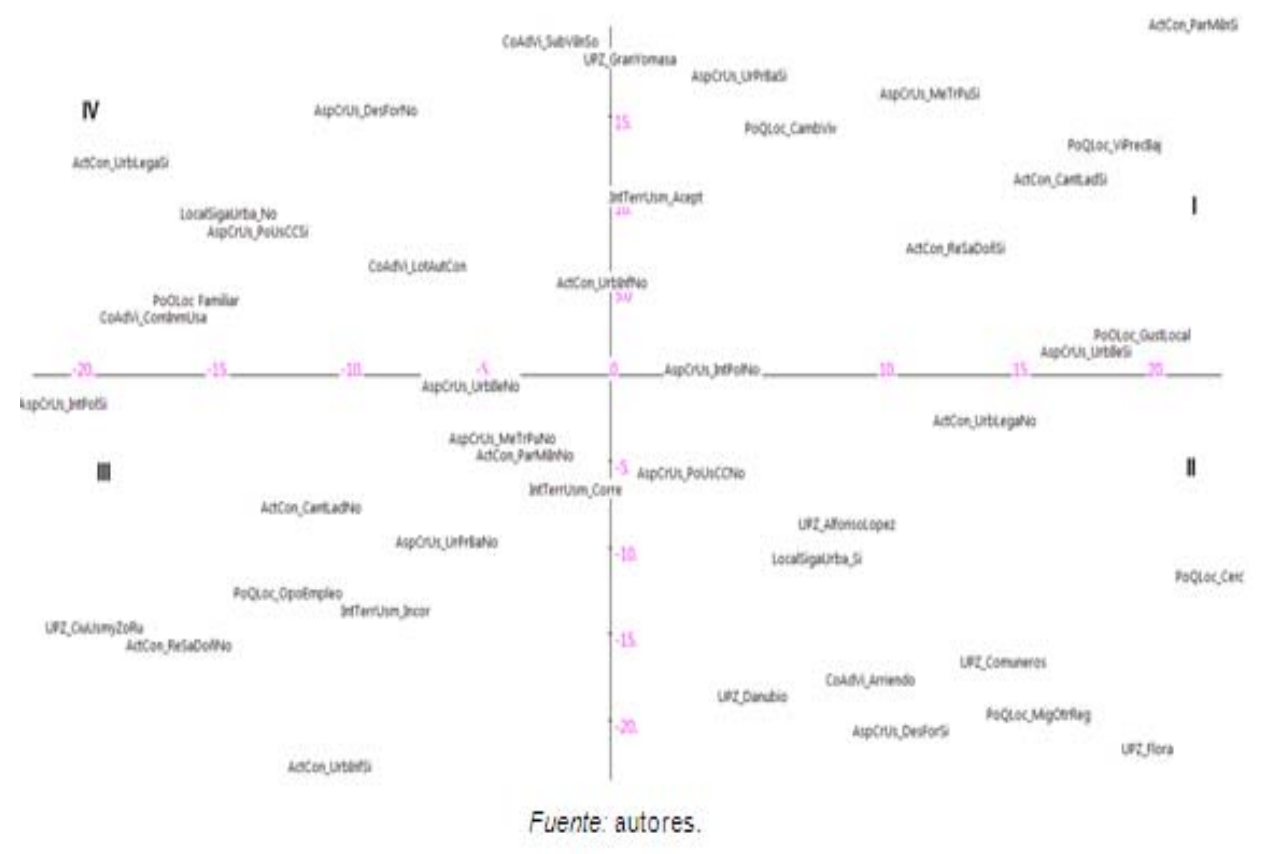

Figura 9. Plano factorial variables. DtmVic 5.7.

Haga clic sobre la imagen para ampliarla

Para el grupo 3, el Parque Minero Industrial es la principal actividad contaminante, asimismo, la urbanización a precios bajos es el factor al que se le atribuye el crecimiento de la localidad. La vivienda en este grupo se obtuvo por medio de la modalidad de interés social. Este grupo considera que la forma en que se intervino u ocupó la localidad fue de manera aceptable y, finalmente, la UPZ que se asocia a este grupo es Gran Yomasa (Tabla 3).

Por otro lado, el grupo 4 se caracteriza por considerar la urbanización informal como una actividad contaminante, por el contrario no consideran el RSDJ como problemática ambiental y, por último, establecen el desplazamiento forzado como un factor importante para el crecimiento de la localidad. Para finalizar, el grupo 5 se caracteriza porque la población vive en arriendo, a su vez, determinan que el RSDJ es la principal actividad contaminante, por el contrario la urbanización legal e ilegal no genera problemáticas. Atribuyen el crecimiento al desplazamiento forzado y a la urbanización ilegal. En este sentido, establecen que la forma de intervenir el territorio fue de forma incorrecta y, finalmente, la UPZ que representa este grupo es Comuneros (Tabla 3).

En la Figura 9, la variable que determina el eje factorial $X$ o factor 1 , en su parte positiva, es ActCon_ReSaDoñSi, ya que esta presenta mayor contribución. Esta variable define a la población de la UPZ Comuneros, pues ellos identifican que los 
impactos del RSDJ es la actividad más contaminante en la localidad. En contraste, la variable que define el eje factorial $X$ en su parte negativa, es AspCrUs_PoUsCCSi, que asocia como factor de crecimiento de la localidad a la construcción del Centro Comercial Altavista y el Portal Usme. Por su parte, la variable que define al eje $Y$ en su parte positiva, es la UPZ Gran Yomasa, esta es la que más cerca está del centro del plano y caracteriza a los encuestados que viven en ella, los cuales son el $39 \%$ de la encuesta. A diferencia de la variable ActCon_UrbInfNo, que define la parte negativa del eje $\mathrm{Y}$, que precisa a la población que no cree que la urbanización informal sea una actividad contaminante. Se puede resaltar, entonces, que el factor 1 o eje $X$ está relacionado con el tema ambiental relevante, como es el caso del RSDJ, y el factor 2 o eje $\mathrm{Y}$ está relacionado con la ocupación territorial, y el tema de la urbanización informal como una actividad que no es contaminante para la población.

\section{DISCUSIÓN}

Los resultados de la entrevista piloto evidencian que existe una relación entre las dimensiones y categorías que la estructuraron, y las variables que explican los conflictos ambientales, que inciden en la calidad de vida de la población, y a su vez los cambios percibidos por la población están relacionados con la gestión pública en la localidad. De acuerdo a Ortiz (2013), la relación entre estas dimensiones y categorías permite entender las aproximaciones de las transformaciones del territorio, desde una visión integral, en donde se refleja la complejidad de los procesos urbanos en los ambientes transicionales.

Según los resultados de la tipificación de la población frente al proceso de ocupación, se puede inferir que la forma de ocupar el territorio no fue homogénea en la localidad, con lo que se pudo generar grupos de acuerdo a sus percepciones. Por el contrario, Gómez-Martínez, Gutiérrez-Montes \& Declerck (2013) encontraron en su estudio que la percepción de los diferentes grupos de productores ganaderos, con respecto a la relación de biodiversiad y calidad del agua, es muy similar, lo que favorece la toma de desiciones y la elaboración de proyectos y programas, sin ser necesaria la estratificación o propuestas distintas para cada grupo.

Las diferencias en los grupos encontrados se deben a que los nuevos barrios, pertenecientes a la UPZ Alfonso López y Comuneros, en donde la vivienda 
informal marca la tendencia, se caracterizan porque fueron corriendo la franja amarilla y se asentaban en el borde urbano-rural (Zambrano, 2005). Si bien, los barrios antiguos de la localidad como los son el barrio Danubio, Santa Librada, Santa Martha y Barranquillita, también se ocuparon de manera informal, en la actualidad se encuentran legalizados, y su manejo del suelo de acuerdo a la clasificación del Plan de Ordenamiento Territorial es residencial de urbanización incompleta (SDA, 2008). No obstante, barrios como Marichuela, Aurora Sector I y II, La Andrea y Valles de Cafam, pertenecientes a la UPZ Gran Yomasa, se caracterizan por ser planificados mediante desarrollos de vivienda de interés social, los cuales se encuentran en zonas destinadas para uso residencial (SDP, 2011). En consecuencia, la población encuestada en cada UPZ responde de manera diferente y asocia variables específicas de acuerdo a cómo se ha intervenido la localidad (Zambrano, 2011).

De esta manera, el clúster 1 permitió caracterizar a los habitantes de la zona rural y Ciudad Usme. Este grupo asoció variables propias que no se repetían en otros grupos. La población encuestada determinó que el principal problema de la localidad es la urbanización de tipo legal que se lleva a cabo con la operación estratégica Nuevo Usme, que construirá vivienda de interés social y privada en veredas como La Requilina, Olarte y Chiguaza (SDA, 2007). Esta urbanización, en cabeza de Metrovivienda, quiere competir con los desarrollos de tipo informal en la localidad. No obstante, para la SDP (2013), la ocupación del suelo en la Región Metropolitana de Bogotá obedece a variables como: las decisiones locales de habilitación del suelo y la operación del mercado inmobiliario, esto también coincide con Zuluaga $(2005,2008)$, en donde la variable principal para el fenómeno de urbanización en la ciudad de Medellín ha sido el mercado inmobiliario acompañado del desarrollo de vías que promueven el transporte privado. Sin embargo, para la población, la zona rural y campesina es patrimonio histórico y ancestral, que será desplazada por un tipo de construcción que no encaja con el paisaje de la zona (Hospital de Usme, 2003). De esta manera, la operación estratégica Nuevo Usme - Eje de integración Llanos Orientales, al albergar una gran masa de población, representa presión sobre la base ecológica y ambiental de soporte de la cuenca del río Tunjuelo, y por supuesto de la sabana de Bogotá, como es el caso de las fuentes de agua, los suelos de potencial agropecuario, la conservación de los cerros orientales del sur y los reductos de vegetación natural que se conservan en la localidad de Usme (Pérez, 2000; Santamaría, 2005; SDA, 2007; Bahamón, 2009). También se identificó, en la fase de campo, que los pobladores de la zona rural sienten que las oportunidades laborales se reducen para ellos, pues la población foránea está captando todas las fuentes laborales, no 
quedando otra opción para los autóctonos que migrar a otras regiones del país 0 , en su defecto, ven la localidad de Sumapaz como opción de subsistencia. Ortiz (2013) encontró en su investigación en la vereda de Chuntame, Cajicá, que la variable percibida por la población frente al fenómeno de la rururbanización es la transformación urbana, producto del desplazamiento de la población local, para dar paso a los nuevos habitantes que, por lo general, tienen mayor poder adquisitivo.

Por otra parte, el clúster 2 presentó diferentes variables, y es que para este conglomerado el desplazamiento forzado no fue la causa del crecimiento de la localidad, sino la mejora del transporte público (Zuluaga, 2008), que se reflejó en la construcción del Portal de Usme y Centro Comercial Altavista. Precisamente la anterior variable para la población de Usme es vista como positiva en términos de desarrollo comercial para la localidad, atribuyéndole una forma diferente de ocupar el territorio. En oposición, para el clúster 4 el desplazamiento forzado sí jalona el crecimiento de la localidad.

El clúster 3 mostró que, en la UPZ Gran Yomasa, la principal forma de adquirir vivienda fue por medio de los subsidios de interés social, que para la localidad fueron dados por el Instituto de Crédito Territorial. Esto es natural, pues es en esta UPZ donde se ubican las urbanizaciones de interés social que existen en la localidad. Para este grupo, la causa del crecimiento de la localidad son los precios bajos de la vivienda, siento apta exclusivamente para estratos bajos (Metrovivienda, 2011). Diferente a este conglomerado, se encuentra el clúster 5, representado por la UPZ Comuneros, en donde la forma de adquirir vivienda es por medio del alquiler, y determinan que la urbanización de tipo informal o legal no genera ninguna problemática.

Otra de las variables identificadas en el proceso de ocupación, de acuerdo a los resultados, es la urbanización de tipo ilegal, predominante en la localidad (SDA, 2007). Este tipo de urbanización, de acuerdo a Zambrano (2005), se debe a tres factores: a) la alta demanda de tierras que se contraponían al sistema de la gran hacienda, b) el conflicto armado que suscitaba el país, c) la incipiente urbanización de la ciudad que jalonaba la expansión urbana, hacia zonas agrícolas. Por su parte, Buitrago \& Carvajal (2005) determinan que la urbanización en Bogotá estuvo caracterizada por la bipolarización norte-sur que sufrió la ciudad. Para Díaz (2009) la urbanización de tipo informal se denomina "Marginalidad Social Urbana", resultado de la violencia política del país. En donde los inmigrantes, ante la necesidad de solventar la escasez de vivienda y prestación de servicios básicos, recurrían a la protesta y a la toma de terrenos públicos y privados para ser 
habitados. Esta urbanización ilegal, en la localidad de Usme, ha generado un cambio de uso del suelo, pues esta se caracteriza por ocupar zonas de ronda, zonas rurales y ecosistemas estratégicos (SDA, 2007; Zuluaga 2008; Bahamón, 2009).

Los resultados mostraron que el Parque Minero Industrial no es una problemática muy conocida en la localidad, pues el $62 \%$ de los encuestados no la asoció como actividad contaminante. Sin embargo, esta actividad en la localidad de Usme y Ciudad Bolívar se desarrolla desde los años 70, debido a la declaración de los cerros orientales como reserva forestal productora, lo cual permitió su aprovechamiento, con actividad minera hasta la actualidad. Sin embargo, esta actividad se ha convertido en un factor de deterioro de la calidad de vida de la comunidad, debido a los focos de olores que se forman en los pozos de agua en las canteras, así como la contaminación del aire con material particulado, y afectación ecológica y paisajística (Ordóñez, Ángel \& Lozano, 2012).

Se identificó, en la pregunta de reconocimiento de las actividades que generan conflicto ambiental, que en muchos de los casos no era de fácil reconocimiento para la población. Es el caso de los habitantes de la UPZ La Flora, que no asociaron ninguna problemática ambiental, pero establecieron como relevante la inseguridad que se vive en la zona. Por su parte, la problemática del Relleno sanitarios Doña Juana, es la más evidente en la localidad, identificada por el 43\% de la población, pues para la memoria colectiva el derrumbe de 1997 generó diversas afectaciones a la salud, y es así como lo argumenta Quimbayo (2007), pues tras el derrumbe de 800 toneladas de basura del relleno, los habitantes de la zona se enfrentaron a una de las mayores tragedias ambientales que ha sufrido el Distrito Capital. Según los estudios de la Universidad del Valle (2006) en la localidad de Ciudad Bolívar, los niños que habitan en áreas circundantes del relleno tienen menor peso en comparación con niños de su misma situación socioeconómica.

Los resultados señalan que el $37 \%$ de la población encuestada está de acuerdo con que la localidad siga urbanizándose, en esta pregunta se identificó que la población atribuye mayor desarrollo, creación de empleo y seguridad si se sigue construyendo vivienda en la localidad. Por su parte, la población que no está de acuerdo con la urbanización (28\%) argumenta que se están agotando las zonas verdes y el área natural, a su vez las actividades agrícolas van a desparecer de la zona. Lo anterior, está relacionado con el tiempo de vivir en la localidad, y es que la población que habita desde hace menos de 10 años está de acuerdo con la 
urbanización, mientras que los que habitan entre 20 a 30 años no están de acuerdo con ella. Finalmente, de acuerdo a Martínez, Echavarría, González \& Martínez (2009), el análisis de conglomerado permitió agrupar a los encuestados según sus percepciones, lo que posibilita un tratamiento diferenciado para abordar los problemas sociales, económicos y ambientales.

\section{CONCLUSIONES Y RECOMENDACIONES}

Las variables principales, identificadas en el proceso de ocupación urbano-rural en la localidad de Usme, por medio de la entrevista piloto, se resumen en: gestión de entidades públicas, percepción de cambios, cambios de uso del suelo, acceso a la salud, empleo en la localidad, forma de adquisición de vivienda, afectación del RSDJ, y recursos naturales afectados, que en el análisis de redes permitieron interpretar aproximaciones de la forma de ocupación del territorio y que responden a los componentes y dimensiones de la sustentabilidad territorial.

La aplicación de la encuesta y la tipificación de sus resultados, reflejó las diferentes opiniones de la población local, frente a variables del proceso de ocupación, con lo que se pudo definir grupos o clúster de acuerdo a las similitudes y coincidencias de cada respuesta. Por lo tanto, se puede señalar que se percibe de manera diferenciada la forma de ocupación de la localidad y, a su vez, las condiciones socioambientales que se dan en cada zona. Específicamente, se pudo agrupar por UPZ, ya que esta fue la forma escogida de muestreo, sin embargo en el transcurso de la investigación se identificó que se puede hacer este mismo análisis tomando como unidad muestral los barrios de acuerdo a la formalidad en su aparición y su prestación de servicios públicos.

Se puede señalar que la ocupación del territorio en la localidad de Usme se ha caracterizado por fenómenos sociopolíticos, como es el caso del desplazamiento forzado, que se enmarca dentro de un abandono del Estado en la gestión de la vivienda para la población vulnerable. A raíz de esto, se crean terceros que intervienen en la compra de terrenos en la localidad, a precios bajos para la población recién llegada en búsqueda de vivienda, en donde se fomenta la apropiación de terrenos no aptos para uso residencial. No obstante, existen otras variables, como la generación de empleo a partir de las canteras, ladrilleras y cementeras, que propició que los trabajadores de las mismas establecieran sus viviendas cerca a su lugar de trabajo, generando barrios informales con carencia 
de servicios públicos. De esta manera, en la localidad la tendencia en la adquisición de vivienda es la compra de lote y posterior autoconstrucción.

Se pudo determinar que existe conflicto y confusión en determinar y priorizar las actividades impactantes al ambiente, pues muchos de los habitantes no las identificaban y les era difícil reconocerlas. Por otro lado, de acuerdo a la zona de la localidad, se estableció la problemática ambiental relevante. En este caso, los barrios Barranquillita y Santa Marta de la UPZ Gran Yomasa, determinaron que la mayor problemática son las canteras y ladrilleras, debido a las fábricas muy cercanas a sus viviendas. Frente al Parque Minero Industrial, los habitantes de barrios como La Aurora y Santa Librada de la UPZ Gran Yomasa reconocieron su afectación, dada su cercanía. El tema de la urbanización informal, en barrios como Santa Librada, Marichuela y La Aurora, no se percibió, pues estos se ubican dentro los proyectos de vivienda planificada de la localidad, a diferencia de barrios como Brazuelos, Monte Blanco y Alfonso López, de la UPZ Comuneros, en donde sí se identificó como problemática ya que los asentamientos se conformaron a partir de la autoconstrucción. Por último, la urbanización de tipo legal, específicamente los proyectos de vivienda de interés social y privados en la zona rural, solo se consideró relevante para los barrios de la UPZ Ciudad Usme, las veredas Chiguaza y Olarte, precisamente por estar en el área directa del proyecto.

Se estableció que el $37 \%$ de población encuestada está de acuerdo con que la localidad siga urbanizándose, esto permite establecer que para una proporción de la población de Usme la expansión urbana no es un problema sino, por el contrario, una oportunidad para jalonar el desarrollo, comercio y seguridad en la localidad, ya que esto genera más oportunidades de empleo, mayor prestación de servicios y atención del Estado.

La población entrevistada determinó que el recurso natural que se encuentra más afectado es el recurso agua, por la baja conciencia de la población, ya que los asentamientos urbanos vierten residuos sólidos y líquidos en las fuentes de agua $y$, a su vez, el RSDJ contamina con lixiviados la cuenca baja del río Tunjuelo. En este sentido, las entrevistas y encuestas arrojaron que el RSDJ es una de las principales actividades impactantes en la localidad, generando malos olores, enfermedades y vectores que, además de afectar la salud humana, generan condiciones de segregación para la población cercana al área de influencia.

Los conglomerados muestran que existen dos percepciones en la forma de intervenir u ocupar el territorio, la primera es de forma incorrecta (19\%) asociada a 
los habitantes de la zona rural y Ciudad Usme, quienes no están de acuerdo con la forma de ocupación de la localidad. Sin embargo, esta forma incorrecta se relacionó con la construcción de vivienda en zonas de montaña y zonas de ronda de protección de ríos, propias de los desarrollos informales en la localidad. La segunda, se establece como forma aceptable (20\%), que se vio reflejada en la UPZ Gran Yomasa, en donde se encuentra urbanizaciones de tipo legal, por lo tanto la población no conoce la problemática de la ocupación en otras UPZ de la localidad.

\section{AGRADECIMIENTOS}

Se agradece a la Maestría en Desarrollo Sustentable y Gestión Ambiental, y al grupo INDESOS de la Universidad Distrital Francisco José de Caldas, por el apoyo y acompañamiento a esta investigación.

\section{POTENCIAL CONFLICTO DE INTERESES}

No hay ningún tipo de conflicto de intereses respecto a la publicación de este artículo, el cual es elaborado a partir de los resultados de la tesis de maestría de la autora Evelin Langebeck Cuéllar, con el asesoramiento como director del autor Julio Beltrán Vargas.

\section{FUENTES DE FINANCIACIÓN}

Programa de Estímulos a la Investigación Thomas van der Hammen. Jardín Botánico José Celestino Mutis, Subdirección Científica, Bogotá.

\section{REFERENCIAS}

- Alcaldía Mayor de Bogotá. (2004). Recorriendo Usme. Bogotá D.C.: Secretaría Distrital de Planeación. 
- Alcaldía Mayor de Bogotá. (2011). 21 Monografías de las localidades. Usme. Bogotá D.C: Secretaría Distrital de Planeación.

- Bahamón, G. (2009). Análisis del proceso de delimitación de espacialidades urbanas, estudio de caso en Medellín. Medellín: Universidad Nacional de Colombia.

- Buitrago, O., \& Carvajal, N. (2005). La dimensión regional en los planes de ordenamiento territorial en el área metropolitana de Bogotá. Actas L. de V., 28.

- Cano, M. (2012). Percepción sobre las dinámicas rural-urbanas en el corregimiento de San Sebastián de Palmitas. (Tesis de magíster). Universidad Nacional de Colombia, Medellín, Colombia.

- Conpes 3305. (2004). Lineamientos para Optimizar la Política de Desarrollo Urbano. Bogotá D.C.: Ministerio de Ambiente, Vivienda y Desarrollo Territorial.

- Crivisqui, E. (1999). Programme de Recherche et Enseignementen Statistique Appliquée. Recuperado de http://www.ulb.ac.be/assoc/presta/esp.html

- DANE. (2007). Bogotá. Proyecciones de Población 2005-2015, según edades quinquenales y simples y por sexo. Bogotá: Secretaría Distrital de Planeación - Departamento Administrativo Nacional de Estadística.

- Dematteis, G., \& Governa, F. (2005). Territorio y Territorialidad en el Desarrollo Local. La Contribución del Modelo SLOT. Boletín de la A.G.E., 39, 31-58.

- Díaz, C. (2009). Algunas características del proceso de urbanización de bogotá desde 1950 hasta finales del siglo XX, una mirada desde la marginalidad social urbana. Revista Latinoamericana de Estudiantes de Geografía, 1, 4-110.

- Echavarría, J. (2013). Calculadora para el tamaño de muestra y error (documentos de trabajo). Escolme, Medellín, Colombia. 
- Fernández, R. (2000). Gestión Ambiental de Ciudades. Teoría crítica y aportes metodológicos. Buenos Aíres: Programa de las Naciones Unidas para el Medio Ambiente.

- Gallopín, G. (2006). Sostenibilidad del desarrollo en América Latina y el Caribe: cifras y tendencias Honduras. Santiago de Chile: CEPAL.

- Giménez, G. (2001). Cultura, territorio y mirgraciones. Aproximaciones teóricas.Alteridades, 11(22), 5-14.

- Gómez-Martínez, M. J., Gutiérrez-Montes, I., \& Declerck, F. (2013). Percepción local acerca de la calidad del agua y la herpetofauna en fincas ganaderas del municipio de Matiguás, Nicaragua. Luna Azul, 38, 30-57. Recuperado de http://www.scielo.org.co/scielo.php?script=sci_arttext\&pid=S190924742014000100003

- Grande, I., \& Abascael, E. (2005). Análisis de Encuestas. Madrid: ESIC Editorial.

- Gutiérrez, C., \& Peña, J. (1996). La percepción geográfica como factor en el desarrollo local. Última Década, 4, 1-06.

- Hernández, R., Fernández, C., \& Baptista, P. (1997). Metodología de la Investigación. Naucalpan de Juárez: McGraw-Hill.

- Hospital de Usme. (2003). Diagnóstico local en salud con participación local. Bogotá: Hospital de Usme.

- Hospital de Usme. (2011). Diagnóstico social de salud con participación social. Bogotá: Alcaldía Mayor de Bogotá.

- Lebart, L., \& Piron, M. (2013). Práctica del análisis de los datos numéricos y textuales con Dtm-Vic. Recuperado de http://www.dtmvic.com/doc/Dtm-VicCast_04_2013.pdf

- Martin, R. (2000). Estadística y Metodología de la Investigación. Madrid: Universidad Autónoma de Barcelona. 
- Martínez, J., Echavarría, P., González, V., \& Martínez, N. (2009). Propuesta Metodológica para el análisis de la sostenibilidad en la provincia de Cuenca. Boletín de la A.G.E., 49, 281-308.

- Metrovivienda. (2011). Poblamiento y Territorio. En Metrovivienda, Usme: Hisotria de un territorio (pp. 11-39). Bogotá.

- Muñoz, J. (2003). Análisis cualitativo de datos textuales con ATLAS.ti. Barcelona: Universitad Autónoma de Barcelona.

- ONU. (2014). World Urbanization Prospects: The 2014 Revisión, Highlights. New York: United Nations, Departament of Economic and Social Affairs, Population División.

- Ordóñez, M. C., Ángel, A. E., \& Lozano, D. P. (2012). A través de la ventana: una apreciación paisajística de los efectos de la minería en los cerros de Bogotá. En C. Toro, J. Fierro, S. Coronado, T. Avendaño (Eds.), Minería, territorio y conflicto en Colombia(pp. 381-395). Bogotá: Universidad Nacional de Colombia.

- Ortiz, D. (2013). Análisis desde la base del conocimiento local de las percepciones y respuestas locales frente al proceso de rurbanización en la vereda de Chuntame, municipio de Cajicá, Cundinamarca. Propuestas para una planificación territorial con participación social (tesis de maestría). Universidad Distrital Francisco José de Caldas, Bogotá, Colombia.

- Ortiz, J., \& Hernández, Y. (2015). Análisis desde la base del conocimiento local de las percepciones y respuestas locales frente al proceso de rurbanización en la vereda de Chuntame, municipio de Cajicá, Cundinamarca. Cuadernos de Geografía: Revista Colombiana de Geografía 24, 101-119.

- Pardo, E., Ortiz, J., \& Cruz, D. (2012). Análisis de datos textuales con Dtm Vic. XXII Simposio Internacional de Estadística (pp. 1-42). Bucaramanga: Universidad Nacional de Colombia.

- Pérez, A. (2000). Expansión urbana de Bogotá. (trabajo de investigación) Instituto de Estudios Urbanos, Bogotá, Colombia. 
- Quimbayo, G. (2007, 27 de septiembre). 10 años de la Tragedia Ambiental de Doña Juana.Más allá del ecologismo. Recuperado de http://gquimbayo.wordpress.com/2007/09/27/10-anos-de-la-tragedia-ambientalde-dona-juana/

- Rodríguez, M. de L., López, J., \& Vela, G. (2013). Indicadores ambientales biofísicos a escala detallada para la planeación territorial en Milpa Alta, Centro de México.Investigaciones Geográficas, Boletín del Instituto de Geografía, UNAM, 80, 21-35.

- Santamaría, C. (2005). Planeación Distrital a la cabeza del más ambicioso plan del sur de Bogotá. En CCB, Pasado, presente y futuro de la localidad de Usme (pp. 89-104). Bogotá: Cámara de Comercio de Bogotá.

- SDA. (2007). Diagnóstico POMCA Tunjuelito. Bogotá: Secretaría Distrital de Ambiente.

- SDA. (2008). Agenda Ambiental Localidad 5 Usme. Bogotá: Secretaría Distrital de Ambiente.

- SDP. (2011). Monografías de las localidades. Localidad \#5 Usme. Bogotá: Secretaría Distrital de Planeación.

- SDP. (2013). Región Metropolitana de Bogotá: Una visión de la ocupación del suelo. Bogotá: Secretaría Distrital de Planeación y Alcaldía Mayor de Bogotá.

- Ther Ríos, F. (2012). Antropología del Territorio. Polis, 11(32), 493-510.

- Universidad del Valle. (2006). Evaluación del Impacto del Relleno Sanitario Doña Juana en la salud de grupos poblacionales en su área de influencia. Bogotá: Unidad Especial de Servicios Públicos, Secretaría Distrital de Salud.

- Varguillas, C. (2006). El uso del ATLAS.ti y la creatividad del investigador en el análsis cualitativo de contenido UPEL. Instituto Pedagógico Rural El Mácaro. Laurus, 12, 73-87. 
- Vera, B., Camino, P., Baez, A., \& Lerdon, J. (2002). Tipologías que caracterizan a un grupo de microempresas de la ciudad de Valdivia Chile. Valdivia: Instituto de Economía Agraria, Facultad de Ciencias Agrarias, Universidad Austral de Chile.

- Winchester, L. (2006). Gestión Urbana para el desarrollo sostenible en América Latina. CEPAL/PNUMA División de asentamientos humanos.

- Zambrano, F. (2005). Pasado, presente y futuro de la localidad de Usme. En CCB, Usme: Urbanización y cambios en la vida urbana (pp. 9-85). Bogotá: Cámara de Comercio de Bogotá.

- Zambrano, F. (2011). Bogotá: Siglo XXI. En Profamilia, Encuesta Distrital de Demografía y Salud (pp. 9-29). Bogotá: Asociación Probienestar de la Familia Colombiana.

- Zuluaga, G. P. (2005). Dinámicas territoriales en frontera rural-urbana en corregimiento de Santa Elena, Medellín. (tesis de maestría). Universidad Nacional de Colombia, Medellín, Colombia.

- Zuluaga, G. P. (2008). Dinámicas urbano-rurales en los bordes de la ciudad de Medellín.Gestión y Ambiente, 11(3), 161-171.

1. Magíster en Desarrollo Sustentable y Gestión Ambiental. Investigadora INDESOS - Universidad Distrital Francisco José de Caldas. Bogotá, Colombia.evelin.langebeck@gmail.com. ORCID: 0000-0003-2243-0899.

2. Ph.D. en Ciencias - Biología, línea biodiversidad y conservación. Docente Maestría en Desarrollo Sustentable y Gestión Ambiental, Universidad Distrital Francisco José de Caldas - Director grupo de investigación INDESOS. Bogotá, Colombia. jebeltran@udistrital.edu.co. ORCID: 0000-0002-9397-7894.

3. "La Unidad de Planeamiento Zonal -UPZ-, tiene como propósito definir y precisar el planeamiento del suelo urbano, respondiendo a la dinámica productiva de la ciudad y a su inserción en el contexto regional, involucrando a los actores sociales en la definición de los aspectos de ordenamiento y control normativo a escala zonal' (Artículo 49 del Decreto 190 de 2004 POT)" (Alcaldía Mayor de Bogotá, 2011). 
Para citar este artículo: Langebeck-Cuéllar, E., \& Beltrán-Vargas, J. (2016). Tipologías de percepción, bajo criterios de sustentabilidad territorial, del proceso de ocupación urbano-rural: localidad quinta de Bogotá. Revista Luna Azul, 43, 415447.

http://200.21.104.25/lunazul/index.php?option=com_content\&view=article\&id=207

Esta obra está bajo una Licencia de Creative Commons Reconocimiento CC BY

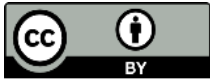

